\title{
SOME ASPECTS OF THE MODERN ANTIHYPERTENSIVE DRUG THERAPY AND MOST COMMON SIDE EFFECTS
}

\author{
Petko Marinov, Kaloyan Georgiev, Marieta Georgieva \\ Department of Preclinical and clinical sciences, Sector Pharmacology and Toxicology, \\ Faculty of Pharmacy, Medical University of Varna, Bulgaria
}

\begin{abstract}
Hypertension or high blood pressure is one of the most common diseases worldwide affecting people and is a major risk factor for stroke, myocardial infarction, vascular disease, and chronic kidney disease. Health care professionals must not only identify and treat patients with hypertension but also should have a good understanding of the side effects that accompany antihypertensive therapy. The aim of this review is to represent the most common adverse drug reactions (ADRs) of the most prescribed antihypertensive drugs.
\end{abstract}

Keywords: hypertension, blood pressure, antihypertensive drugs, ACE inhibitors, beta-blockers, diuretics, calcium blockers

\section{INTRODUCTION}

Arterial hypertension (AH) is one of the most socially significant diseases. It is largely related to morbidity, disability and mortality of the population. The incidence of hypertension varies between 4.8 and $30.3 \%$ in different countries and geographical areas. In the large epidemiological study PURE (Prospective Urban Rural Epidemiology), conducted in 17 countries on five continents, the incidence of hypertension is $40.7 \%$ and only $13.1 \%$ of patients were with controlled hypertension (1). In our country $15 \%$ of the population over 18 years of age suffers from hypertension. The disease affects both sexes and the percentage of hypertensive patients increases with age.

\footnotetext{
Address for correspondence:

Petko Marinov

Faculty of Pharmacy,

Medical University of Varna,

55 Marin Drinov Str.

9002 Varna, Bulgaria

e-mail: eurohospital.bg@abv.bg
}

Received: April 27, 2015

Accepted: May 19, 2015
The aims of modern antihypertensive therapy are not only limited to reduction and normalization of blood pressure (BP), but also have to lower the cardiovascular risk of patients (2). All hypertensive patients, including those on medical treatment, should make changes in their lifestyle designed to control risk factors and in order to reduce the doses of antihypertensive drugs. Changes in lifestyle, which help to decrease blood pressure and total cardiovascular risk, are smoking cessation, reducing and maintaining a healthy weight, reducing alcohol and sodium chloride intake, increased physical activity, increased intake of fruits and vegetables, decreased intake of saturated and total fat (3). The latest guidelines for management of arterial hypertension $(2,4$, 5) recommend initiation of antihypertensive therapy for patients with systolic blood pressure $\geq 140 \mathrm{~mm}$ $\mathrm{Hg}$ or diastolic blood pressure $\geq 90 \mathrm{~mm} \mathrm{Hg}$. The positions on the time of initiation of antihypertensive drug therapy are similar: AH II degree (5) or AH II or III degree (2), treatment should begin immediately, while AH I degree can wait to assess the effect of non-pharmacologic methods. Pharmacological therapy is recommended for patients with $\mathrm{AH} \mathrm{I} \mathrm{de-}$ gree when there is organ damage as in type 2 diabetes, cardiovascular disease or chronic kidney disease 
(2). According to the management of Joint National Committee (JNC) 8 Hypertension Guidelines (4) the initial antihypertensive therapy should include a thiazide-type diuretic, a calcium channel blocker (CCB), an angiotensin-converting enzyme inhibitor (ACEI) or an angiotensin receptor blocker (ARB), as each of those class drugs have comparable positive effects on overall mortality, cardiovascular, cerebrovascular and renal adverse events, with the exception of heart failure, wherein the thiazide-type diuretics have more pronounced prophylactic efficacy. JNC 8 does not recommend a beta-blocker as an initial selection of antihypertensive therapy, as well as alphablockers, mixed alpha $/$ /beta-blockers (e.g. carvedilol), vasodilating beta-blockers (e.g. nebivolol), central al$\mathrm{pha}_{2}$-adrenergic agonists (e.g. clonidine), direct vasodilators (e.g. hydralazine), aldosterone receptor antagonists (e.g. spironolactone), peripherally acting adrenergic antagonist (e.g. reserpine) and loop diuretics (e.g. furosemide). European Society of Hypertension (ESH) and European Society of Cardiology (ESC) added to the major classes of antihypertensive drugs beta blockers and points out that they are all suitable for initiating and maintaining antihypertensive therapy, as monotherapy or combined with each other. One of the main advantages of five antihypertensive classes is their ability to lower blood pressure by different mechanisms. Therefore, they can be effectively combined with each other and their antihypertensive effect is additive. The only exception is the combination of two blockers of the renin-angiotensin-aldosterone system (RAAS), which is associated with increased incidence of renal side effects and hyperkalemia. Therefore, this combination is not recommended (6). Priority should be given to drugs that are administered once daily and have a long-lasting effect ( $\geq 24$ hours). Monotherapy achieves target levels of BP in a small number of patients and thereforethe most of them require combination therapy. Initial treatment usually is a monotherapy or a combination of two drugs at low doses, with a consequent increase in the number of doses and drugs, if necessary. Fixed dose combinations of two drugs can bring additional benefits with the easy regimen. Despite that the "first-line agents" lately are not applied, most guidelines recommend initiation of antihypertensive therapy with RAAS blocker or calcium channel blocker, indicating that the initial choice should comply with accompanying diseases. Finally, JNC 8 emphasizesthe need for the clinician to motivate patients to be compliant and adhere to their medication regimen.

Pharmacologic treatment of hypertension relies heavily on the above five major antihypertensive drug classes, each with its advantages and disadvantages. Each class of antihypertensive medication has specific advantages and contraindications in specific clinical situations. The choice of a particular drug is individual for each patient, taking into account the accompanying diseases (7) (table 1).

Table 1. Preferred antihypertensive drugs for specific conditions

\begin{tabular}{lll}
\hline $\begin{array}{l}\text { Condition } \\
\text { Hypertension in patients with diabetes mellitus }\end{array}$ & Drug of choice \\
$\begin{array}{l}\text { Hypertension in patients with peripheral vascular } \\
\text { disease }\end{array}$ & CCBs \\
$\begin{array}{l}\text { Hypertension in patients with angina pectoris } \\
\begin{array}{l}\text { Hypertension in patients with renal impairment/ } \\
\text { microalbuminuria }\end{array}\end{array}$ & Beta blockers or CCBs \\
$\begin{array}{l}\text { Hypertension in patients with end stage renal disease/ } \\
\text { albuminuria }\end{array}$ & $\begin{array}{l}\text { ACEIs or ARBs (dialysis patients), loop diuretics } \\
\text { Aypertension in patients with heart failure }\end{array}$ & $\begin{array}{l}\text { ACEIs or ARBs, beta-blockers (carvedilol, nebivo- } \\
\text { lol, metoprolol, bisoprolol), diuretics, aldosterone } \\
\text { antagonists }\end{array}$ \\
$\begin{array}{l}\text { Hypertension in older patients } \\
\mathbf{8}\end{array}$ & \begin{tabular}{l} 
Diuretics or CCBs \\
\hline
\end{tabular} & $\begin{array}{l}\text { Scripta Scientifica Pharmaceutica, vol. 2, №1, 2015, pp. 7-14 } \\
\text { Copyright } \odot \text { Medical University of Varna }\end{array}$
\end{tabular}


Petko Marinov, Kaloyan Georgiev, Marieta Georgieva

\section{Diuretics}

Diuretics are one of the major classes of antihypertensive medication and are among the most prescribed ones. Their antihypertensive effect is a result of reduced plasma volume and peripheral vasodilatation. Recently diuretics are rarely used as monotherapy, but are usually part of combination therapy with RAAS blockers. Different classes of diuretics, representatives of various groups and the most common side effects are listed in Table 2. of systolic blood pressure and the risk of cardiovascular events is higher compared to chlorthalidone. Greater effectiveness of chlorthalidone than HCTZ is strongly suggested by post hoc analysis of the MRFIT (Multiple Risk Factor Intervention Trial) data, which showed better outcomes with chlorthalidone (6).

\section{ACE inhibitors (ACEIs)}

They are established and effective drugs for the treatment of hypertension, by lowering peripheral vascular resistance due to decreased production

Table 2. Classification of the group of diuretics and its specific adverse effects

\begin{tabular}{|c|c|c|}
\hline Class of diuretics & Drugs & Adverse drug reactions (ADRs) \\
\hline Thiazides & Hydrochlorothiazide & $\begin{array}{l}\text { - } \downarrow \mathrm{K}^{+}, \mathrm{Na}^{+}, \mathrm{Mg}^{2+} \\
\text { - } \uparrow \mathrm{Uric} \text { acid and can trigger gout attack } \\
\text { - } \uparrow \mathrm{Ca}^{2+}\end{array}$ \\
\hline Thiazide-like & Chlorthalidone, Indapamide & $\begin{array}{l}\text { - } \uparrow \text { LDL, total cholesterol and total triglycerides } \\
\text { - Other - rashes, pancreatitis, photosensitivity, } \\
\text { weakness, sexual dysfunction }\end{array}$ \\
\hline Loop diuretics & $\begin{array}{l}\text { Furosemide, Torsemide, } \\
\text { Bumetanide }\end{array}$ & $\begin{array}{l}\downarrow \mathrm{K}^{+}, \mathrm{Na}^{+}, \mathrm{Mg}^{2+}, \mathrm{Ca}^{2+} \\
\text { Ototoxicity } \\
\text { Hyperuricemia } \\
\text { Dizziness }\end{array}$ \\
\hline $\begin{array}{l}\text { Potassium sparing } \\
\text { diuretics }\end{array}$ & $\begin{array}{l}\text { Spironolactone, Eplerenone, } \\
\text { Triamterene, Amiloride }\end{array}$ & $\begin{array}{l}\text { Hyperkalemia } \\
\text { Hyponatremia } \\
\text { Gynecomastia (Spironolactone) } \\
\text { Weakness, fatigue, dizziness }\end{array}$ \\
\hline
\end{tabular}

Frequency of ADRs of thiazide and thiazidelike diuretics decreases in dose reduction manner and in combination with ACE - inhibitors. Hypokalemia increases the toxicity of cardiac glycosides. Ototoxicity of furosemide is increased when co-administered with aminoglycosides, carboplatin, cisplatin and paclitaxel. It may cause photosensitivity. There is a danger for both groups (thiazide and loop diuretics) of cross-allergy reactions to sulfonamides. In renal insufficiency can be used indapamide or furosemide. Amiloride and triamterene, due to weak antihypertensive effect are used in combined diuretic preparations for retention of potassium.

In clinical practice, the most often prescribed diuretic is hydrochlorothiazide (HCTZ). It is also the major component of the combined antihypertensive drugs. However, it is less effective in the reduction of angiotensin II. In plasma, synthesized in the kidney renin, cleaves four amino acids from circulating angiotensinogen, which is synthesized in the liver, to form the biologically inactive decapeptide angiotensin I. Angiotensin-converting enzyme (ACE) cleaves two amino acidsfrom angiotensin I to form the biologically active octapeptide (1-8) angiotensin II. Angiotensin II exerts its effects by binding to two $G$ protein-coupled receptors, the angiotensin type $1\left(\mathrm{AT}_{1}\right)$ and angiotensin type $2\left(\mathrm{AT}_{2}\right)$ receptors. The predominant angiotensin receptor in the vasculature is the $\mathrm{AT}_{1}$ receptor. Activation of the $\mathrm{AT}_{1}$ receptor leads to vasoconstriction, cell growth, aldosterone secretion, and catecholamine release, whereas activation of the $\mathrm{AT}_{2}$ receptor leads to vasodilation, inhibition of cell growth, natriuresis, and bradykinin release. Inhibition of ACE enzyme leads to decreased production of angiotensin II, which is the reason of reduced ac- 
tivity of sympatico-adrenal system, secretion of aldosterone and antidiuretic hormone, and thereby lowering sodium and water retention. Main representatives are: Captopril, Enalapril, Lisinopril, Fosinopril, Quinopril, Ramipril, Perindopril, Moexipril, Trandolapril. The group is very suitable for treatment of $\mathrm{AH}$ and concomitant diseases likemetabolic syndrome, diabetes mellitus (DM), chronic heart failure $(\mathrm{CHF})$, renal failure, and ischemic heart disease. The most common ADRs are:

* Dry irritating cough, which occurs in up to $20 \%$ of those taking ACEIsand is thought to be due to inhibition of bradykinin breakdown (because ACE is identical to kininase II, ACEIs may also leadto elevation of bradykinin levels in some tissues)

* Angioedema occurs in less than 1\% of patients. The reason is the same like previously mentioned - accumulation of endogenous bradykinin. Drug withdrawal is necessary and some patients may require drug treatment and/or emergent intubation.

* Hyperkalemia (should not be administered in creatinine clearance below $30 \mathrm{ml} / \mathrm{min}$ ).

- Rare side effects - skin rashes, dysgeusia (an alteration in or loss of taste), proteinuria (membranous nephropathy), neutropenia (symptoms include sore throat and fever) (18).

ACEIs are contraindicated in bilateral renal artery stenosis and pregnancy, due to renal agenesis and fetal death.

\section{AT1 receptor blockers (ARB)}

They selectively block angiotensin II - receptor type 1 - AT 1 . It has been shown that they are as effective as ACEIs in reduction of blood pressure, the degree of proteinuria and slowing the progression of renal disease and heart failure. RAAS blockade implemented by both classes of drugs reduces equally cardiovascular risk (8). Key representatives of the ARB are: losartan, valsartan, candesartan, eprosartan, irbesartan, telmisartan. The overall rate of adverse events was comparable, although ACE inhibitors were associated with a greater risk for cough. The adherence to the therapy with ACE inhibitors and ARBs is high (>90\%), but the persistence with ARDs is better than ACE inhibitors (8). Actually, ARBs are the class of antihypertensive drugs with the best persistence due to their good tolerance (9). The most common ADRs are:

* Headache, dizziness, fatigue, somnolence, vertigo, anxiety, depression, lightheadedness, drowsiness

* Skin rashes, pruritus

* Nausea, vomiting, diarrhea, abnormal hepatic function, hepatitis

* Hyperkalemia, hyponatremia

* Myalgia, paresthesia

* Leukopenia, agranulocytosis, anemia, neutropenia

Like ACEIs, use of ARBs is contraindicated in pregnant women because of the association of RAAS blockade with increased fetal morbidity and mortality, particularly with exposure during the second and third trimester.

It is assumed that telmisartan is very suitable for the treatment of hypertension with concomitant metabolic syndromeon one hand by improving haemodynamic response and on the other hand bylowering the risk of developing insulin resistance and type 2 diabetes mellitus. The mechanism is not fully elucidated, but it is believed that it is associated with the modulation of peroxisome proliferator-activated receptor (PPAR) (13).

The newest representative of the RAAS blockers is the direct renin inhibitor - aliskiren, which binds the proteolytic site of renin, thereby block conversion of angiotensinogen to angiotensin I, thus reducing the consequent production of angiotensin II. The antihypertensive effect is comparable to that of ACEIs and ARBs. Aliskiren can cause mild gastrointestinal symptoms such as diarrhea observed at high doses (600 mg daily), and can also cause cough and angioedema, but probably less often than ACE inhibitors. The combination with the other RAAS blockers is not recommended, since it increases the incidence of adverse effects on renal function.Like other RAAS inhibitors, aliskiren is not recommended in pregnancy.

\section{Calcium channel blockers (CCBs)}

They are a heterogeneous group of antihypertensives, blocking the entry of calcium through the cell membranes of vascular smooth muscle cells and cardiac myocytes. Their hypotensive effect is mainly 
Petko Marinov, Kaloyan Georgiev, Marieta Georgieva

due to the reduction in peripheral vascular resistance (dihydropyridine and non-dihydropyridine) and the both pre- and post-capillary vasodilatation may underlie the reduced clinical incidence of pedal edema,

Table 3. Classification of the group of calcium channel blockers and its specific adverse effects

$\begin{array}{lll}\text { Class of CCBs } & \text { Drugs } & \text { Adverse drug reactions (ADRs) } \\ & & \text { Tachycardia } \\ \text { Nifedipine, Nitrendipine, Felodip- } & \text { Headache, dizziness } \\ \text { ine, Amlodipine, Lercanidipine, } & \text { Peripheral edema } \\ \text { Lacidipine } & \text { Flush } \\ & \text { Gingival hyperplasia } \\ & \text { Bradycardia } \\ & \text { AV block } \\ & \text { Constipation (Verapamil) } \\ & \text { Contraindicated in sever systolic } \\ & \text { Verapamil, Diltiazem } & \text { dysfunction } \\ & & \text { Gingival hyperplasia } \\ & \text { Headache, flushing and edema } \\ & \text { occur less frequently than } \\ & \text { dihydropyridine }\end{array}$

reduction of heart rate (non-dihydropyridine). The main groups of calcium channel blockers and their most frequent side effects are given in Table 3.

For the treatment of hypertension retard dosage forms of dihydropyridinesare are preferred. Non-retard forms are dangerous in acute forms of coronary artery disease. Non-dihydropyridines (verapamil and diltiazem) should not be combined with betablockers - risk of severe bradycardia and AV block. They are also contraindicated in AF (atrial fibrillation) + WPW (Wolf-Parkinson-White) syndrome. All CCBs can cause gingival hyperplasia, a rare side effect that is reversible if detected early but can lead to several dental problems if the CCB therapy is not suspected as the cause.

Amlodipine is a dihydropyridine CCB from the third generation and is the most commonly prescribed agentfrom the group ofCCBs. In recent years some new third generation CCBs appeared on the market, as lercanidipine, lacidipine and manidipine. CCBs may differ, however, in their ability to modulate blood flow through the renal afferent and efferent arterioles. In preclinical studies, lercanidipine, a third-generation antagonist, dilates both efferent and afferent arterioles and reduces intraglomerular pressure and the degree of proteinuria, and thus mimics the action of the inhibitors of RAAS. An action on the most common side effect ofcalcium antagonists, seen with lercanidipine relative to other 1,4-dihydropyridines (19). Addition of lercanidipine to antihypertensive therapy with RAAS blocker leads to further benefits for renal function $(10,11)$. Prescription of third generation CCBs is associated with improvements in adherence and persistence to antihypertensive therapy. The degree of compliance with the prescribed treatment regimen approximates that of RAAS blockers. Treatment with lercanidipine overcomes some of the problems associated with the use of other CCBs, such as uneven therapeutic effect, reflex sympathetic stimulation, and significantly reduces the side effects associated with vasodilation.

\section{Beta-blockers}

Beta-blockers are particularly suitable in hypertensive patients with coronary artery disease, some arrhythmias, heart failure and glaucoma. The use of beta-blockers is questionable and they lose ground in some modern guidelines for management of hypertension because of their weak ability to prevent the occurrence of strokes and their negative effects on the metabolic profile. Not all beta-blockers have the same properties and side effects. The main groups of beta-blockers and their most frequent side effects are given in Table 4. 
Some aspects of the modern antihypertensive drug therapy and most common side effects

Table 4. Classification of the group of beta-blockers and its specific adverse effects

\begin{tabular}{|c|c|c|}
\hline Class of Beta blockers & Drugs & Adverse drug reactions (ADRs) \\
\hline Non-selective beta blockers & $\begin{array}{l}\text { Propranolol, Sotalol, } \\
\text { Timolol }\end{array}$ & $\begin{array}{l}\text { Bronchospasm (caution with asthma and } \\
\text { COPD) }\end{array}$ \\
\hline Selective beta1-blockers & $\begin{array}{l}\text { Metoprolol, Atenolol, Bi- } \\
\text { soprolol, Betaxolol }\end{array}$ & $\begin{array}{l}\text { Bradycardia (caution with AV block) } \\
\text { Peripheral vasospasm (especially non-selective } \\
\text { beta blockers) }\end{array}$ \\
\hline $\begin{array}{l}\text { Beta blockers with vasodilating } \\
\text { properties }\end{array}$ & Carvedilol, Nebivolol & $\begin{array}{l}\text { Neurological - weakness, fatigue, } \\
\text { vivid dreams, nightmares, and rarely - } \\
\text { hallucinations (lipid soluble beta blockers) } \\
\text { Reduced glycose tolerance, mask signs of } \\
\text { hypoglycemia } \\
\uparrow T G \text { (especially non-selective beta blockers) } \\
\text { Impotence }\end{array}$ \\
\hline
\end{tabular}

They are contraindicated in obstructive pulmonary disease and AV block II and III degree. The side effects are reduced in cardioselective beta blockers. More recent data suggest that cardioselective beta blockers are safe with moderate or severe chronic obstructive pulmonary disease (COPD) (12) and confirm the efficacy and safety of selective beta-blockers in patients with cardiovascular diseases and COPD (14).

$$
\text { Alpha } a_{1} \text {-bockers }
$$

The main representatives are: Prazosin, Doxazosin, and Terazosin. They are used for treatment of hypertension and prostatic hypertrophy, and do not have adverse metabolic effects. ADRs include:

* Orthostatic syncope

* Phenomenon of the first dose - with vertigo, dizziness, headache, palpitations.

- Addiction (prazosin)

* Swelling, fatigue, weakness

* Sleepiness, depression

It is not necessary to adjust the dosage of doxazosin in patients with renal failure.

\section{Alpha ${ }_{2}$-agonists}

The group is used very rarely in modern therapy due to the serious side effects. The main representatives are clonidine, methyldopa and reserpine.

* Clonidine is suitable for renal failure. Its ADRs include dry mouth, depression, lethargy, bradycardia, fatigue, orthostatic, rebound-phenomenon interruption.

* Methyldopa is preferred for hypertension during pregnancy. Its ADRs are hepatotoxicity, auto- immune reactions, allergic reactions, hemolytic anemia, leukopenia, and thrombocytopenia.

* Reserpine is rarely used nowadays. Its ADRs are serious and include depression, nightmares, suicidal attempts, parkinsonism, drowsiness, impaired vision, bradycardia, hyperacidity, nasal congestion.

\section{Antagonists of the imidazole receptors}

Representatives of this group of antihypertensive drugs are rilmenidin and moxonidin. There was no described rebound phenomenon. ADRs include:

* Nervous system - anxiety, restlessness, insomnia, depression, impaired thought processes, vertigo, dizziness, drowsiness, fatigue.

* Gastrointestinal events with nausea, constipation, diarrhea, stomach pain.

* Allergic reactions

* Decreased libido

\section{Direct vasodilators}

This group reduces blood pressure by decreasing peripheral vascular resistance. The main representatives include hydralazine and minoxidil. They are used in refractory hypertension, hypertensive crisis, and hypertension in pregnancy, preeclampsia and eclampsia. ADRs include:

* Hydralazine - tachycardia, orthostatic, headache, drug-induced lupus, depression, nausea, vomiting, diarrhea.

* Minoxidil - dizziness, hypotension, electrocardiogram changes, tachycardia, sodium

* and water retention, gynecomastia, hair growth. 
Petko Marinov, Kaloyan Georgiev, Marieta Georgieva

Resistant hypertension is considered when a treatment strategy involving a change in lifestyle, diuretic and antihypertensive drug from two different classes, failed to lead to a decrease in blood pressure $<140 / 90 \mathrm{~mm} \mathrm{Hg}$. For its treatment is recommended alpha 1 blocker, peripheral vasodilators, mineralocorticoid receptor antagonists, centrally acting drugs. In absence of effectiveness of the medical treatment of resistant hypertension ESH recommends some invasive procedures such as renal sympathetic denervation and baroreceptor stimulation performed in specialized centers.

\section{CONCLUSION}

The therapy of hypertensive patients should be carried out at any age, including patients over 80 years of age. It has been shown that therapeutic regimens designed to lower blood pressure below 150/80 $\mathrm{mm} \mathrm{Hg}$ in the elderly, reduce the risk in total mortality, stroke and cardiovascular events, while there are proven benefits and lack of influence to the risk for fractures, dementia, depression and quality of life (15).

Individual approach, consistency with comorbidities, the tolerability profile of prescribed drugs and persistence of the patient are the basis for successful treatment of hypertension. The commitment to antihypertensive therapy reduces by $20 \%$ the risk of a cardiovascular disease (16). Prescribing many drugs with different modes of application, especially in the presence of another concomitant chronic diseases requiring medication, is the reason of discounts of patient's persistence and termination of the prescribed treatment. It has been shown that fixed combinations significantly improve commitment to treatment and allow better control of blood pressure and fewer side effects (17), improving tolerability, and is economically more advantageous. Preferred combinations in recent years include the RAAS blocker, a diuretic and a calcium antagonist. Combining RAAS blocker with a diuretic has shown additive effect preferably in hypertensive patients with heart failure, renal failure, and post-stroke disorders. The combination of RAAS blocker with a calcium antagonist has also an additive effect and is very suitable in hypertensive patients with the metabolic syndrome, a high risk of developing diabetes, ischemic heart disease, peripheral angiopathies, post-stroke, advanced age, and isolated systolic hypertension. The combination of a beta-blocker and a diuretic has an additive antihypertensive effect, but its use is limited because of adverse metabolic effects of the two classes of drugs, which are reduced in vasodilating betablockers. This combination is used for hypertensive patients with heart failure, rhythm pathology, and ischemic heart disease.

\section{REFERENCES}

1. Chow CK, Teo KK, Rangarajan S, Islam S, Gupta $\mathrm{R}$ et al. Prevalence, Awareness, Treatment and Control of Hypertension in Rural and Urban Communities in High-, Middle- and Low-Income Countries. JAMA. 2013 Sep 4;310(9):959-68.

2. Mancia G, Fagard R, Narkiewicz K, Redon J, Zanchetti A et al. 2013 ESH/ESC guidelines for the management of arterial hypertension. Eur Heart J. 2013 Jul;34(28):2159-219.

3. 2007 Guidelines for the management of arterial hypertension. Journal of Hypertension, 2007; 25: 1105-1187.

4. James PA, Oparil S, Carter BL, Cushman WC, Dennison-Himmelfarb Cet al. 2014 Evidencebased guideline for the management of high blood pressure in adults: report from the panel members appointed to the Eighth Joint National Committee (JNC 8). JAMA. 2014 Feb 5;311(5):507-20.

5. Weber MA, Schiffrin EL, White WB, Mann S, Lindholm LH, et al. Clinical practice guidelines for the management of hypertension in the community. A statement by the American Society of Hypertension and the International Society of Hypertension. J Clin Hypertens (Greenwich). 2014 Jan;16(1):14-26.

6. Roush GC, Holford TR, Guddati AK: Chlorthalidone compared with hydrochlorothiazide in reducing cardiovascular events: Systematic review and network metaanalyses.Hypertension 59:1110, 2012.

7. Law M., Morris J., Wald N. Use of blood pressure lowering drugs in the prevention of cardiovascular disease: meta-analysis of 147 randomised trials in the context of expectations from prospective epidemiological studies. BMJ. 2009;338:b1665.

8. Matchar DB, McCrory DC, Orlando LA, Patel MR, Patel UD, Patwardhan MB, Powers B, Samsa GP, Gray RN. Systematic review: comparative effectiveness of angiotensin-converting enzyme 
Some aspects of the modern antihypertensive drug therapy and most common side effects

inhibitors and angiotensin II receptor blockers for treating essential hypertension. Ann Intern Med. 2008;148:16-29.

9. Burke TA et al. Discontinuation of antihypertensive drugs among newly diagnosed hypertensive patients in UK general practice. J Hypertens 2006;24:1193-1200.

10. Burnier M. Renal protection with calcium antagonists: the role of lercanidipine. Curr Med Res Opin. 2013 Dec;29(12):1727-35.

11. Robles N., Romero B., Garcia de Vinuesa E. et al. Treatment of proteinuria with lercanidipine associated with renin-angiotensin axis-blocking drugs. Renal Failure. 2010;32 (2):192-197.

12. Mainguy V, Girar D, Maltais F. Effect of bisoprolol on respiratory function and exercite capacity in chronic obstructive pulmonary disease. Am J Cardiol. 2012;10(2):258-263.

13. Furukawa H, Mawatari K, Koyama K, Yasui S, Morizumi R, Shimohata T, Harada N, Takahashi A, Nakaya Y.Telmisartan increases localization of glucose transporter 4 to the plasma membrane and increases glucose uptake via peroxisome proliferator-activated receptor $\gamma$ in 3T3-L1 adipocytes. EurJPharmacol. 2011 Jun 25;660 (2-3):485-91.

14. Stefan MS, Rothberg MB, Priya A, Pekow PS, $\mathrm{Au}$ DH, Lindenauer PK. Association between beta-blocker therapy and outcomes in patients hospitalized with acute exacerbations of chronic obstructive lung disease with underlying ischaemic heart disease, heart failure or hypertension.

Thorax. 2012 Nov;67(11):977-84.

15. Peters R, Beckett N, McCormack T, Fagard R, Fletcher A, Bulpitt C. Treating hypertension in the very elderly-benefits, risks, and future directions, a focus on the hypertension in the very elderly trial. Eur Heart J. 2014 Jul;35(26):1712-8.

16. Chowdhury R, Khan H, Heydon E, Shroufi A, Fahimi S, Moore C, Stricker B, Mendis S, Hofman A, Mant J, Franco OH. Adherence to cardiovascular therapy: a meta-analysis of prevalence and clinical consequences. Eur Heart J. 2013 Oct;34(38):2940-8.

17. Gupta AK, Arshad S, Poulter NR.Compliance safety and effectiveness of fixed dose combinations of antihypertensive agents: a meta analysis. Hypertension. 2010 Feb;55(2):399-407.
18. Wong J, Patel RA, Kowey PR. The clinical use of angiotensin-converting enzyme inhibitors. ProgCardiovasc Dis. 2004;47:116-30.

19. Messerli FH. Calcium antagonists in hypertension: from hemodynamics to outcomes, Amer. J. Hypertension. 2002;15;94S-97S. 